\title{
用分子沉技术获得 $10^{-10} \mathrm{~Pa}$ 的极高真空
}

\author{
达道安 姜万顺 杨益民 周坤粦 \\ （兰州物理研究所）
}

目前用液氮冷冻钛升华阱的方法获得 $10^{-10} \mathrm{~Pa}$ 的压力是可信的. 作者运用他们关于极高 真空中气体分子运动理论的研究结果 ${ }^{[1]}$, 在实验中解决了分子沉技术的应用问题. 并把玻璃 管型弯注规改为陶瓷裸式弯注规, 将铇灯丝改为敷氧化针铇灯丝. 经过最佳的系统运转, 在一 个 $\phi 400 \times 500 \mathrm{~m} / \mathrm{m}$ 的柱形不锈钢容器中稳定地获得了 $4 \times 10^{-11} \mathrm{~Pa}$ 的极高真空.

\section{一、系统的结构及特点}

系统的结构如图 1 所示. 该系统由主容器、极高真空室、加热装置、冷冻装置及抽气设备 等组成. 主容器包括内壳和外壳两部分, 均由不锈钢制成. 外壳尺寸为 $\phi 900 \times 1600 \mathrm{~m} / \mathrm{m}$. 内 壳尺寸为 $\phi 600 \times 1000 \mathrm{~m} / \mathrm{m}$. 内外壳之间的空间称为“夹层”, 其内装有管状加热器和液氮冷 却的紫铜盘管. 极高真空室由不锈钢制成, 尺寸为 $\phi 400 \times 500 \mathrm{~m} / \mathrm{m}$, 其结构为双壁式的, 用 以败存液氮. 在极高真空室的内部和外部, 各装有一个钛钼合金丝做的钛升华拼和泵。出口 处装有一个百叶窗式的障板。测量用裸调制 B-A 规和裸弯注规亦装在极高真空室内. 加热

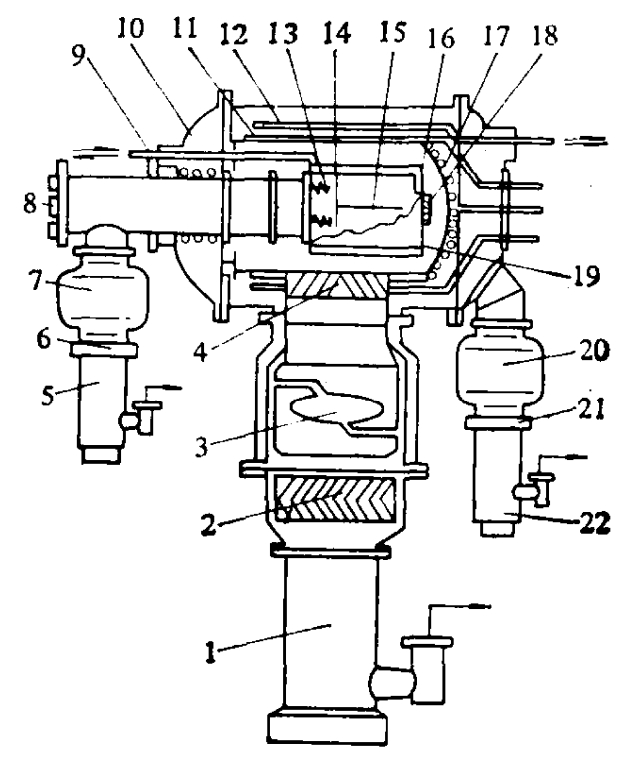

图 1 极高真空系统结构示意图

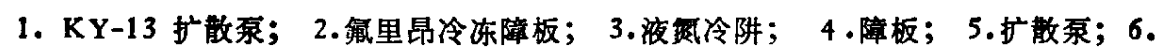
障板；7. 冷吽；8. 测量法兰；9.极高室进出液口；10.容器外売；11.中壳液实 盘管；12.管加热器；13.规管；14. 铜百叶窗障板；15.小钝泉；16.极高室； 17. 容器中壳； 18.百叶窗障板；19.大钎恶；20.冷阱；21.障板；22.KY-9 扩散原

本文 1986 年 5 月 12 日收到. 
装䁂包括管状加热器和空气加热器两部分. 前者用来加热外壳、内壳和极高真空室; 后者用来 烘烤主扩散百上面的液氮冷阱. 冷冻装置由氧里昂致冷系统和开式液氮供给系统组成。前者 冷冻主扩散百上面的障板及端法兰的橡胶密封圈;后者供给冷拼、内壳和极高真空空液氮.

抽气设备由三个相互独立的分系统组成,即“央层”抽气系统“隧道”抽气系统和“主”抽气 系统. “夹层”抽气系统是真空保护系统，工作压力为 $10^{-3} \sim 10^{-5} \mathrm{~Pa}$. 其作用是减小漏气和漏 热. “隧道”系统是测量引线的保护真空通道,该系统内的压力为 $10^{-4} \sim 10^{-5} \mathrm{~Pa}$. “主”抽气系 统同主容器和极高真空室相连, 并由机械原、 KY-11 和 KY-13 两级扩散葲、人字形氟里昂

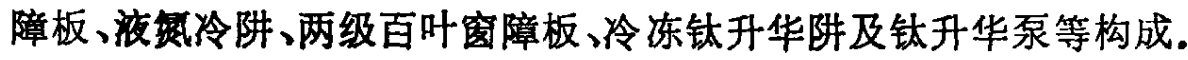

\section{二、压力的测早}

选用了两种真空规来测量极高真空室的压力. 一种是调制 B-A 规, 型号为 IMR-103, 规管灵敏度常数为 $0.188 / \mathrm{Pa}$, 配有巴尔蔡司公司生产的全自动数字显示超高真空电离计. 另 一种是本所研制的陶瓷裸式弯注规,规管灵敏度常数为 $0.105 / \mathrm{Pa}$. 微电流测量采用日本产的 TR-84M 振簧式静电计. 以上两种规管均经国防科工委真空计量一级站校准.

在测量技术方面，我们着重作了以下改进:

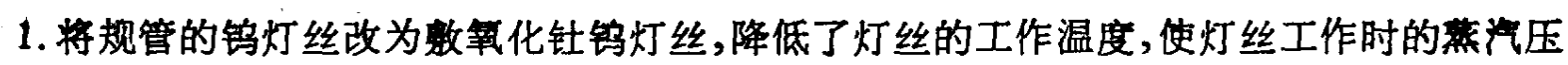
由 $10^{-10} \mathrm{~Pa}$ 降低到 $10^{-2 \mathrm{Da}} \mathrm{Pa}$ 以下. 结果列于表 $1^{[2]}$.

2. 解决了弱小电流测量中的绝缘、屏蔽及接地等一系列技术问题，可靠、稳定地测量了 $10^{-13} \mathrm{~A}$ 的弱小电流.

表 1 钨灯丝和数䂇化针铇灯丝工作参数比较

\begin{tabular}{|c|c|c|c|c|c|c|}
\hline 灯丝 & 发射电流 $(\mathrm{mA})$ & 0.5 & 1.0 & 2.0 & 4.0 & 10 \\
\hline \multirow{3}{*}{ 铇 } & $U_{f} \times I_{f}(\mathrm{~V} \cdot \mathrm{A})$ & $4.1 \times 1.85$ & $4.45 \times 1.95$ & $4.8 \times 2.05$ & $5.2 \times 2.1$ & $5.8 \times 2.25$ \\
\hline & $w(w)$ & 7.6 & 8.7 & 9.01 & 10.9 & 13 \\
\hline & $T(\mathrm{~K})$ & 2183 & 2263 & 2298 & 2348 & 2433 \\
\hline \multirow{3}{*}{ 数两化针钨 } & $U_{f} \times I_{f}(\mathrm{~V} \cdot \mathrm{A})$ & $2.6 \times 1.0$ & $2.7 \times 1.0$ & $2.8 \times 1.0$ & $3 \times 1.05$ & $3.3 \times 1.2$ \\
\hline & $w(w)$ & 2.6 & 2.7 & 2.8 & 3.15 & 3.96 \\
\hline & $T(\mathrm{~K})$ & 1517 & 1532 & 1550 & 1602 & 1692 \\
\hline
\end{tabular}

\section{三、系统运转程序}

我们在实验工作中得到了一套运转该系统的最佳程序. 一般,系统要进行预处理, 即先用 干燥㷋气“冲洗”系统, 然后进行低真空“浸泡”。系统烘烤温度约为 $250^{\circ} \mathrm{C}$, 时间约 $36 \mathrm{~h}$. 在系 统整体烘烤时, 必须启动主扩散㫤上的氧里昂障板. 特别需要掌握的是升华钛㬌和测量规管 的彻底去气. 在烘烤过程中,当系统的压力降低到 $10^{-4} \mathrm{~Pa}$ 时，开始间断地对钝原及规管去气， 直到系统完全冷却下来时为止. 当系统的压力降低到 $10^{-9} \mathrm{~Pa}$ 时, 停止去气. 系统的冷冻过程 必须按照从高压力到低压力这样一个程序进行, 最后冷冻极高真空室. 在冷冻过程中应注意 防止“冷漏”现象的出现. 应先启动冷冻钝升华阱, 再启动冷冻钝升华恶, 以形成分子沉环境。两 
者加热功率分别为 $1400 \mathrm{~W}$ 和 $600 \mathrm{~W}$. 它们每次的工作时间皆为 $10 \mathrm{~min}$. 大约工作 3 4 次就足够了. 要注 意消除蒸钛过程中钠膜解吸放出的 甲烷气体，否则不易得到更低的压 力 $^{[3]}$.

\section{四、实验结果}

共进行了 12 次实验, 均稳定地 获得了 $10^{-11} \mathrm{~Pa}$ 的压力. 遂于 1985 年 10 月进行并通过了部级鉴定. 现 将其中三次实验结果列于表 2. 运 转过程中压力的变化由图 2 曲线给 出. 实验测得冷冻钎升华阱的效率 分别为 812 (对氢气) 和 5000 (对氮 气). 分子沉效率为 0.63 .

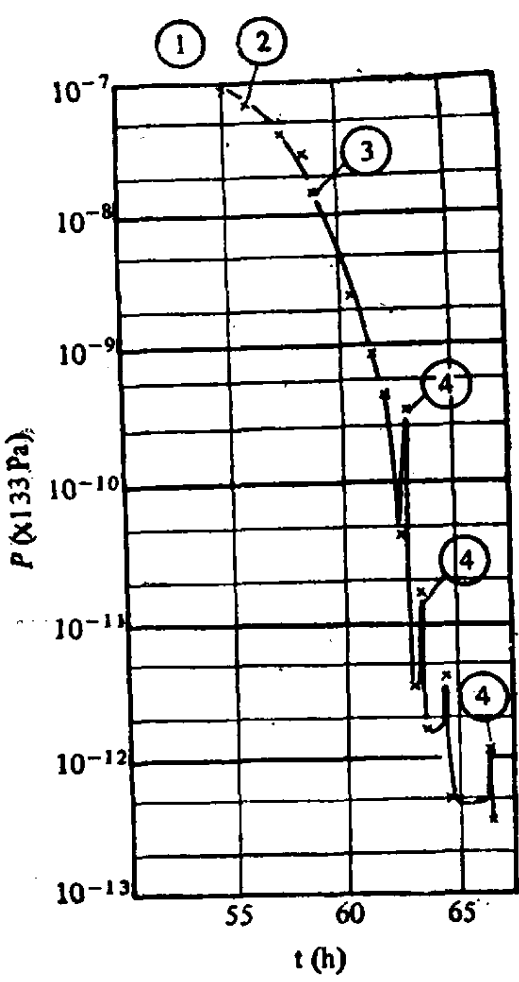

图 2 系统的压力一时间曲线

(1) $48 \mathrm{~h}$ 娂烤与 $7 \mathrm{~h}$ 冷却; (2) 中壳注入 $\mathrm{LN}_{2}$;

(3) 极高室注人 $\mathrm{LN}_{2} ;$ (4)蒸钝

表 2 极限压力实验结果

\begin{tabular}{c|c|c|c}
\hline 实 验 序 & 1 & 2 & 3 \\
\hline 灯丝发射电流 $(\mathrm{mA})$ & 2 & 2 & 2 \\
\hline 静电计高阻 $(\Omega)$ & $10^{12}$ & $10^{12}$ & $10^{12}$ \\
\hline 极限压力测宣值 $(\mathrm{Pa})$ & $6.0 \times 10^{-11}$ & $4.2 \times 10^{-11}$ & $2.1 \times 10^{-11}$ \\
\hline 备 注 & 正常运转 & 正常运转 & 系统经 $\mathrm{LN}_{2}$ 减E \\
\hline
\end{tabular}

致谢: 参加该项工作的尚有杜庆竹、柏文炳、郑建才、崔遂先、毕龙生、张彦伟、陈锡文、逯敬盛、王敏敏、 陈珍、张孝义等同志,特表示感谢.

\section{参考文献}

[ 1 ] Da Dao-an et al,, Proc. 8th. Inter. Vac. Cong., 2(1980), 7.

[2] 达道安等, 中国真空学会第二届年会论文集, 2(1983)，1-4.

[3] Hobson, J. P., Proc. 9th. Inter. Vac. Cong., 1983, 35. 